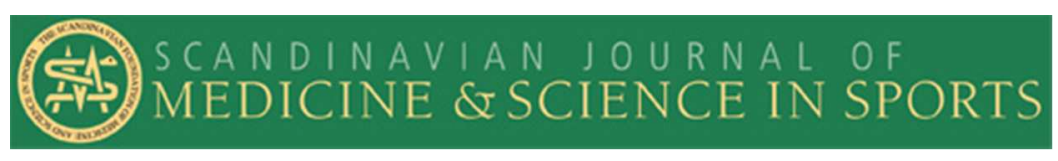

\title{
Myostatin dysfunction is associated with reduction in overload induced hypertrophy of soleus muscle in mice
}

\begin{tabular}{|r|l|}
\hline Journal: & Scandinavian Journal of Medicine and Science in Sports \\
\hline Manuscript ID: & SJMSS-O-308-15.R1 \\
\hline Manuscript Type: & Original Article \\
\hline Complete List of Authors: & n/a \\
\hline & $\begin{array}{l}\text { Minderis, Petras; Lithuanian Sports University, Institute of Sport Science } \\
\text { and Innovations } \\
\text { Kilikevicius, Audrius; Lithuanian Sports University, Institute of Sport } \\
\text { Science and Innovations } \\
\text { Baltusnikas, Juozas; Lithuanian Sports University, Institute of Sport } \\
\text { Science and Innovations } \\
\text { Alhindi, Yosra; University of Aberdeen, School of Medical Sciences } \\
\text { Venckunas, Tomas; Lithuanian Sports University, Institute of Sport Science } \\
\text { and Innovations } \\
\text { Bunger, Lutz; Scotland's Rural College (SRUC), Animal Breeding and } \\
\text { Genetics, Animal and Veterinary Sciences group } \\
\text { Lionikas, Arimantas; University of Aberdeen, School of Medical Sciences } \\
\text { Ratkevicius, Aivaras; University of Aberdeen, School of Medical Sciences }\end{array}$ \\
\hline Keywords: & $\begin{array}{l}\text { Skeletal muscle, muscle hypertrophy, contractile properties, p70S6K, high } \\
\text { resistance exercise }\end{array}$ \\
\hline
\end{tabular}

\section{SCHOLARONE}

Manuscripts 


\section{Myostatin dysfunction is associated with reduction in overload induced hypertrophy of soleus muscle in mice}

P. Minderis ${ }^{1}$, A. Kilikevicius ${ }^{1}$, J. Baltusnikas ${ }^{1}$, Y. Alhindi ${ }^{3}$, T. Venckunas ${ }^{1}$, L. Bunger ${ }^{2}$, A. Lionikas $^{1,3}$, A. Ratkevicius ${ }^{1,3}$

${ }^{1}$ Institute of Sport Science and Innovations, Lithuanian Sports University, Kaunas, Lithuania, ${ }^{2}$ Animal Breeding and Genetics, Animal and Veterinary Sciences group, Scotland's Rural College (SRUC), Edinburgh, UK, ${ }^{3}$ School of Medical Sciences, College of Life Sciences and Medicine, University of Aberdeen, Aberdeen, Scotland, UK

Running title: Myostatin in resistance exercise

\section{Corresponding author:}

Dr. Aivaras Ratkevicius

School of Medical Sciences, College of Life Sciences and Medicine, Applied Health Science Building, University of Aberdeen, Foresterhill, Aberdeen, AB25 2ZD, Scotland, U.K.

Tel: $+44(0) 122438023$

E mail: a.ratkevicius@abdn.ac.uk 


\section{Abstract}

The aim of the study was to investigate if myostatin dysfunction would promote the gain in muscle mass and peak isometric force $\left(\mathrm{P}_{0}\right)$ of soleus muscle $(\mathrm{SOL})$ in response to functional overloading (FO) after ablation of the gastrocnemius muscle. Fifteen male Berlin high (BEH) mice homozygous for the compact mutation causing dysfunction of myostatin and seventeen mice with the corresponding wild type allele $(\mathrm{BEH}+/+)$ were subjected to FO of SOL for 28 days at the age of 14 weeks. Compared to $\mathrm{BEH}+/+$ mice, $\mathrm{SOL}$ of $\mathrm{BEH}$ was heavier (mean \pm SD, $13.5 \pm 1.5$ vs $21.4 \pm 1.8 \mathrm{mg}$, respectively, $P<0.001)$. After FO, SOL mass increased relatively more in $\mathrm{BEH}+/+$ than $\mathrm{BEH}$ strain $(34.9 \pm 11.5$ vs $17.7 \pm 11.9 \%$, respectively, $P<$ 0.01). $\mathrm{P}_{0}$ fell $(P<0.01)$ only in BEH strain which also showed an increase $(P<0.01)$ in optimal muscle length. Specific $\mathrm{P}_{0}$ became even more depressed in BEH compared to $\mathrm{BEH}+/+$ strain $(8.4 \pm 1.4$ versus $10.8 \pm 1.3 \mathrm{~N} / \mathrm{g}$, respectively, $P<0.001)$. Phosphorylation p70 S6 kinase did not differ between the strains. In summary, myostatin dysfunction impairs adaptation of SOL muscle to high functional demands.

Key words: Skeletal muscle, muscle hypertrophy, contractile properties, p70S6K, high resistance exercise 


\section{Introduction}

Skeletal muscle mass is an important factor contributing to health and wellbeing (Wolfe, 2006), and there is a significant interest in ways to promote muscle mass and strength in humans of different ages and health status (Stewart et al., 2013). Much of the debate has recently focused around myostatin (Smith and Lin, 2013).

Myostatin, a member of the TGF- $\beta$ super family, is a potent inhibitor of muscle growth in mammals (McPherron et al., 1997). Mouse models with impaired function of myostatin show an increase in skeletal muscle mass as a result of muscle fiber hypertrophy and hyperplasia (McPherron et al., 1997). Myostatin dysfunction is associated with enhanced mammalian target of rapamycin (mTOR) signalling which induces muscle growth in response to functional overloading (Lipina et al., 2010, Goodman et al., 2011). Phosphorylation of p70 S6 kinase (p70S6K) which is associated with mTOR activation correlates with the increase in muscle mass after resistance training in mice (Baar and Esser, 1999). These observations suggested that inhibition of myostatin could preserve and restore contractile tissue in various muscle wasting conditions. Indeed, intraperitoneal injections of myostatin blocking antibodies induce an increase in muscle mass of dystrophic mouse model (Bogdanovich et al., 2002). There is also evidence that acute resistance exercise decreases myostatin signalling through the activation of the TGF $\beta$ inhibitor Notch (MacKenzie et al., 2013). However, there are doubts about the physiological role of myostatin, as there was no difference in plasma myostatin levels between young men and older men showing significant loss of muscle mass and strength (Ratkevicius et al., 2011). Effectiveness of myostatin inhibition as a treatment against loss of muscle function is unclear. Mice with dysfunctional myostatin show reduced specific force of the extensor digitorum longus (EDL) muscle (Mendias et al., 2006, Amthor et al., 2007). We have observed a reduction in specific force of Xenopus muscle fibers treated 
with SB431542 that acts to inhibit myostatin signaling through Smad transcriptional factors (Watt et al., 2010).

There are large knowledge gaps about the role of myostatin in adaptation of skeletal muscle to exercise. Myostatin dysfunction leads to the shift towards faster contracting myosin isoforms which is the likely mechanism underlying the reduced endurance capacity of myostatin deficient mice (Matsakas et al., 2010). Yet decreased or abolished myostatin signalling might be advantageous for adaptations to resistance training since type II fibres show greater enlargement in the cross sectional area compared to type 1 fibres (Verdijk et al., 2009). However, to the best of our knowledge, this hypothesis has not been tested.

Mouse soleus muscle (SOL) consists primarily of type 1 and type 2A fibers with some $(\sim 10 \%)$ type $2 \mathrm{X}$ fibres and thus differs from the other appendicular muscles in rodents dominated by type 2B, 2X and 2A fibers (Amthor et al., 2007, Bloemberg and Quadrilatero, 2012). This similarity to human muscles (Bloemberg and Quadrilatero, 2012) makes mouse SOL a prudent model for examining the role of myostatin in the adaptive response to resistance training though higher metabolic rate in mice than humans complicates direct comparisons (Darveau et al. 2002). Functional overloading (FO) after synergists ablation has been widely used to study muscle hypertrophy in rodents (Lowe and Alway, 2002). The main aim of our study was to test the hypothesis that myostatin dysfunction would increase the gain in mass and isometric force of SOL after ablation of the gastrocnemius muscle. We studied Berlin High mice which carried either a mutant myostatin alleles known as compact (BEH) or wild type myostatin alleles, BEH+/+ (Amthor et al., 2007, Lionikas et al., 2013).

\section{Materials and methods}

\section{Animals and study design}


All procedures involving mice were approved by the Lithuanian State Food and Veterinary Service (Nr. 0223). Mice were housed in standard cages, one to three mice per cage at a temperature of $22-24{ }^{\circ} \mathrm{C}$ and $40-60 \%$ humidity as in our previous studies (Ratkevicius et al., 2010, Kilikevicius et al., 2012). Animals were fed standard chow diet and received tap water ad libitum. $\mathrm{BEH}+/+$ animals were generated by crossing animals from $\mathrm{BEH}$ and Berlin Low (BEL) strains and then repeatedly backcrossing the offspring to BEH using marker assisted selection for the wild type myostatin (Amthor et al., 2007, Lionikas et al., 2013, Bunger et al., 2004). We used males of the 17th or higher generation of backcrossing, homozygous for the wild type allele of myostatin $(\mathrm{BEH}+/+)$ and male $\mathrm{BEH}$ mice homozygous for the compact allele.

Fifteen $\mathrm{BEH}$ mice and eighteen $\mathrm{BEH}+/+$ mice were subjected to $\mathrm{FO}$ of SOL for 28 days starting at the age of 14 weeks. These animals were anesthetized with an intraperitoneal injection of ketamine $(100 \mathrm{mg} / \mathrm{kg})$ and xylazine $(10 \mathrm{mg} / \mathrm{kg})$, and the gastrocnemius muscle (GAS) was surgically removed from a randomly selected leg using similar methods as described earlier (Hamilton et al., 2010). Mice were given buprenorphine after surgery for pain relief and were monitored on a daily basis. The contralateral SOL of these mice served as internal control (CL-CON) in analysis of muscle mass, p70S6K phosphorylation and cytochrome c levels. Twelve $\mathrm{BEH}+/+$ and twelve $\mathrm{BEH}$ mice were not subjected to any interventions and used as age matched independent controls (CON) in the analysis of muscle length and contractile properties, since this analysis took 40-50 min and could not be carried out on FO and CL-CON muscles at the same time.

\section{Assessment of muscle properties}

Similar procedures as in our previous studies were used (Baltusnikas et al., 2015). Mice were euthanized at 18 weeks of age. Sutures were attached to the proximal and distal tendons of Sol for measurements of contractile properties. The muscle was then excised and fixed 
between two platinum plate electrodes in $50 \mathrm{ml}$ Radnotti tissue bath filled with the Tyrode solution $\left(121 \mathrm{mM} \mathrm{NaCl}, 5 \mathrm{mM} \mathrm{KCl}, 0.5 \mathrm{mM} \mathrm{MgCl}_{2}, 1.8 \mathrm{mM} \mathrm{CaCl}_{2}, 0.4 \mathrm{mM} \mathrm{NaH} \mathrm{PO}_{4}, 0.1\right.$ mM NaEDTA, $24 \mathrm{mM} \mathrm{NaHCO}_{3}, 5.5 \mathrm{mM}$ glucose, $\mathrm{pH}$ adjusted to 7.4 when bubbled with 95 $\% \mathrm{O}_{2}$ and $5 \% \mathrm{CO}_{2}$. The distal tendon of the muscle was attached to a hook and the proximal end was tied directly to the lever of muscle test system (1200A-LR Muscle Test System, Aurora Scientific Inc., Aurora, Canada). The muscle was then left to equilibrate in the solution for $10 \mathrm{~min}$. In the meantime the contralateral soleus muscle was dissected and placed in the Tyroid solution bubbled with $95 \% \mathrm{O}_{2}$ and $5 \% \mathrm{CO}_{2}$. All experiments were carried out at room temperature of $\sim 23{ }^{\circ} \mathrm{C}$. The length of the fixed muscle was increased in steps every $30 \mathrm{~s}$ just after delivery of electrical pulse to evoke a twitch contraction. This procedure was continued until twitch force did not increase with the increase in muscle length. The muscle was then photographed with the length scale in the background to assess muscle length with a precision of $0.1 \mathrm{~mm}$. Muscles were kept at this optimal length during the assessment of contractile properties. Firstly, single twitches were generated and peak twitch force was measured. The twitch contraction time was assessed as the time from the beginning of the contraction to the peak of twitch force. Twitch half relaxation time was measured as the time taken for force to decline from peak to $50 \%$ of peak value. Afterwards, the muscle was subjected to $900 \mathrm{~ms}$ trains of stimuli at $20,50,80,100$ and $150 \mathrm{~Hz}$ for assessment of peak isometric force. Assessment of contractile properties was completed by eccentric exercise consisting of 20 repeated eccentric contractions performed every $10 \mathrm{~s}$. Each eccentric contraction was induced by $1100 \mathrm{~ms}$ stimulation at a frequency needed to generate peak force (80 or $100 \mathrm{~Hz}$ ). During the last $200 \mathrm{~ms}$ of this stimulation a ramp stretch was imposed followed by a $200 \mathrm{~ms}$ gradual return of the muscle to the initial length without any stimulation. The amplitude of the stretch was $30 \%$ of muscle fibre or 2.5 fiber lengths per second assuming fibre length to muscle length ratio of 0.7 (Brooks and Faulkner, 1988). Peak 
isometric force was measured during the initial $900 \mathrm{~ms}$ of contraction. Then these muscles were incubated in $2 \mathrm{ml}$ of Tyrode solution for $2 \mathrm{~h}$ at room temperature. $250 \mu \mathrm{l}$ of Tyrode solution was sampled for assessment of CK activity using biochemical analyser (Spotchem ${ }^{\mathrm{TM}}$ EZ SP-4430, Menarini Diagnostics, UK) with the reagent strips (Arkray Factory, Inc., Shiga, Japan). Following all measurements both control and experimental muscle were freed from tendons, blotted and weighed (Kern, ABS 80-4, Germany). Afterwards, muscles were dried for $48 \mathrm{~h}$ at a temperature of $40{ }^{\circ} \mathrm{C}$ and the weighed again for estimation of dry muscle weight.

\section{Western blotting}

Muscle homogenates were prepared as described previously (Ratkevicius et al., 2010). Then samples containing $50 \mu \mathrm{g}$ protein were loaded on $10 \%$ polyacrylamide gel, separated using SDS-PAGE electrophoresis and transferred to polyvinylidene fluoride (PVDF) membrane. Then membranes were washed with Tris buffered saline (TBS) containing $0.1 \%$ (vol/vol) Tween-20 (TBS-T buffer) before two hour incubation in the blocking buffer $(5 \%$ (wt/vol) non-fat milk in TBS-T buffer). Afterwards the membranes were incubated for $18 \mathrm{~h}$ at $4{ }^{\circ} \mathrm{C}$ with a primary antibody at 1:1000 dilution (vol/vol) in TBS-T buffer supplemented with 5\% bovine serum albumin. All antibodies were from Cell Signaling Technology (Danvers, MA, USA). The following primary antibodies were used; Phospho-p70 S6 Kinase (Thr389) or Pp70S6K (\#9205), p70 S6 Kinase or p70S6K (\#9202), cytochrome c or Cyt C (\#4272) and $\beta$ Actin (\#4967). After incubation with a primary antibody, membranes were washed in TBS-T buffer and exposed for $2 \mathrm{~h}$ to HRP-conjugated secondary antibody (\#7071) at 1:2000 dilution in the blocking buffer. The imaging of blots was performed using ECL reagent (Amersham Biosciences, Buckinghamshire, UK) and Fluor-SMax Imager (Bio-rad, Hertfordshire, UK). The images were quantified using Image (NIH, USA) software.

\section{Statistical analysis}


All data analysis was performed using IBM SPSS Statistics v21 and Prism 5.0 software. The two factor analysis of variance was used with strain $(\mathrm{BEH}$ or $\mathrm{BEH}+/+)$, treatment $(\mathrm{FO}$ or control) as main effects and strain by treatment interaction. A repeated measures design was followed in the analyses of muscle weight (two levels; overloaded and contralateral leg) and fatigue test (twenty levels). A Greenhouse-Geisser correction was applied in the fatigue test data analyses to compensate for the violation of sphericity. All the tests were two tailed with significance level was set at $P<0.05$.

\section{Results}

Table 1 contains data on body mass of $\mathrm{BEH}+/+$ and $\mathrm{BEH}$ mice in the experiments with $\mathrm{FO}$ of SOL muscle. BEH mice were heavier $(P<0.001)$ than $\mathrm{BEH}+/+$ mice. Body mass of mice did not change after FO and did not differ from the age matched controls. Data on muscle mass, optimal length, peak isometric force and specific force are presented in Fig. 1. SOL was heavier in $\mathrm{BEH}$ mice compared to $\mathrm{BEH}+/+$ mice $(P<0.001)$. FO induced a marked gain in SOL mass $(P<0.001)$. When adjusted for the weight of the contralateral SOL, the relative gain in $\mathrm{BEH}+/+$ strain was greater than in $\mathrm{BEH}$ strain (mean \pm S.D., $34.9 \pm 11.5 \%$ vs $17.7 \pm$ $11.9 \%$, respectively, $P<0.01$ ). These changes of muscle weight reflected greater relative gain in dry muscle mass for $\mathrm{BEH}+/+$ compared to $\mathrm{BEH}$ strain $(36.1 \pm 11.8 \%$ versus $16.0 \pm$ $10.5 \%$, respectively, $P<0.01)$. Muscle mass of the contralateral control SOL $(\mathrm{CON}-\mathrm{CL}) \mathrm{did}$ not differ from the muscle mass of the age-matched mice $(\mathrm{CON})$ that were not subjected to FO. There were no differences in optimal muscle length of SOL between BEH and BEH+/+ strains for CON mice. FO induced an increase in the optimal muscle length $(P<0.05)$ for $\mathrm{BEH}$ mice, but not $\mathrm{BEH}+/+$ mice. $\mathrm{BEH}$ strain generated greater peak force $(P<0.01)$ compared to $\mathrm{BEH}+/+$ strain in $\mathrm{CON}$ mice, but the differences between the strains disappeared after FO; BEH mice showed a decrease in peak isometric force while this parameter did not 
change in $\mathrm{BEH}+/+$ mice. Thus FO induced a decrease in specific force in both strains of mice, but specific force was lower in $\mathrm{BEH}$ compared to $\mathrm{BEH}+/+$ mice at each time point $(P<$ $0.001)$.

Twitch contractile properties are shown in Fig. 2. BEH mice generated twitches with shorter contraction time $(P<0.001)$ and half relaxation time $(P<0.001)$ compared to $\mathrm{BEH}+/+$ mice. Twitch to tetanus force ratio was also lower in $\mathrm{BEH}$ mice compared to $\mathrm{BEH}+/+$ mice. FO did not have any significant effect on these twitch properties.

Data on changes in p70S6K phosphorylation and cytochrome c are presented in Fig. 3. There were no significant differences between $\mathrm{BEH}+/+$ and $\mathrm{BEH}$ mice in these measurements. p70S6K phosphorylation did not change after FO. Cytochrome $\mathrm{c}$ to $\beta$-Actin ratio tended to be higher in $\mathrm{BEH}$ mice compared to $\mathrm{BEH}+/+$, but the difference between the strains was not significant $(\mathrm{P}=0.085)$. FO did not induce any change in this ratio.

Data on the peak isometric force during 20 eccentric contractions and CK efflux after the exercise are presented in Fig. 4. Changes in the peak force differed depending on the strain and treatment (strain by treatment by time interaction, $P<0.001$ ). The $\mathrm{BEH}$ muscles showed a greater drop in the peak force than $\mathrm{BEH}+/+$ muscles $(P<0.05-0.0001)$ when studied in the control condition (CON). FO reduced the force loss in BEH muscles to the level of $\mathrm{BEH}+/+$ strain which did not show any changes in the force loss after FO. There were no differences between $\mathrm{BEH}$ and $\mathrm{BEH}+/+$ in muscle $\mathrm{CK}$ efflux after the exercise. Muscle $\mathrm{CK}$ efflux was not modulated by the adaptation to FO.

\section{Discussion}

The main aim of the study was to test the hypothesis that myostatin dysfunction promotes muscle hypertrophy and strength gain in response to FO. We studied the effects of ablation of the gastrocnemius muscle on muscle properties of $\mathrm{SOL}$ in $\mathrm{BEH}$ and $\mathrm{BEH}+/+$ mice. The 
results reject our original hypothesis, since $\mathrm{BEH}$ mice showed smaller rather than greater gain in muscle mass compared to $\mathrm{BEH}+/+$ and exhibited a decrease rather than an increase in peak isometric force after FO. Thus myostatin dysfunction might impair adaptations to increased functional demands in skeletal muscles with high oxidative capacity.

\section{Contractile properties}

SOL of BEH mice showed faster twitch speed and reduced specific force compared to $\mathrm{BEH}+/+$ mice. This high twitch speed could be attributed to a shift in muscle fibre composition towards faster contracting myosin isoforms and fibre types in mice with myostatin dysfunction (Amthor et al., 2007, Matsakas et al., 2010). However, the decrease in specific force is not expected from the changes in muscle fibre composition because type 2 fibres often show higher specific force than type 1 fibres (Bottinelli et al., 1996). It appears that effects of myostatin inhibition are not limited to changes in the fibre type composition. SB431542 mediated inhibition of myostatin signalling lead to an increase in cross sectional area with no change in peak isometric force of muscle fibre in Xenopus laevis (Watt et al., 2010). One of the reasons for a decrease in specific force could be due to low levels of contractile proteins in muscle fibres of mice showing myostatin dysfunction (Qaisar et al., 2012). Enlarged myonuclear domains might limit protein synthesis and accumulation of contractile protein in muscle fibres showing excessive hypertrophy (Qaisar et al., 2012). However, this is an oversimplified view since myostatin inhibits protein synthesis and removal of this inhibition is expected to have a positive effect on the overall protein synthesis rates (Goodman et al., 2013). Interestingly, specific muscle force increased in mice with myostatin knock out after a period of endurance training or food restriction which lead to a decrease in the cross sectional area of skeletal muscles (Matsakas et al., 2012, Matsakas et al., 2013). It has been suggested that accumulation of aberrant $\mathrm{p} 62$ proteins might interfere 
with force generation in muscle fibres of myostatin deficient mice fed ad libitum (CollinsHooper et al., 2015). Interestingly, $\mathrm{BEH}$ and $\mathrm{BEH}+/+$ mice did not differ in specific force of SOL at the age of 31-35 days when muscle mass was less than half of the adult size (Baltusnikas et al. in press). Adult C57BL/6 mice of similar muscle mass as young BEH mice also show no effect of myostatin knock out on specific force of SOL muscle (Mendias et al. 2006). It might be that there is a critical muscle size beyond which muscle hypertrophy interferes with force production causing a decrease in specific force. Biomechanical factors such as an increase in muscle fibre pennation angles might limit force generating capacity of hypertrophied muscles in addition to the factors acting at the single fibre level (Amthor et al., 2007). Effects of myostatin dysfunction might also depend on the background strain of mice. Thus it is important to study effects of myostatin dysfunction using various strains of mice.

\section{Functional overloading (FO)}

We used 4 week exposure to FO. It is a popular model to study muscle hypertrophy in mammals (Lowe and Alway, 2002). This type of muscle overloading leads to an increase in muscle mass with less pronounced increase in force generating capacity in mouse plantaris muscle (Bodine and Baar, 2012). A similar force deficit is observed in skeletal muscles of rats (Kandarian and White, 1989). We focused on SOL which can be excised intact for assessment of contractile properties and contains a mixture of muscle fibre types resembling human muscles (Bloemberg and Quadrilatero, 2012). It is expected that the effects of FO and myostatin inhibition would vary between skeletal muscles that differ in muscle fibre type composition and other properties. SOL showed a relatively small increase in muscle mass and no increase in peak isometric force which is in contrast to the previous findings on plantaris after FO (Bodine and Baar, 2012). The majority of studies on the role of myostatin in rodents focused on the muscles dominated by type 2B fibres (Amthor et al., 2007, Matsakas et al., 
2010, Matsakas et al., 2012). The observed effects of myostatin on the tibialis anterior and extensor digitorum muscles are typically large and stimulated the interest in it as a possible pharmacological target (Mendias et al., 2006). However, human muscles are rather different as no 2B fibres are detected (Smerdu and Erzen, 2001). The present study on the role of myostatin indicated that, contrary to expectation, the potential for gain in muscle mass and function might be limited in the muscles comprised of type 1 and type $2 \mathrm{~A}$ fibres.

A particular feature of adaptation to $\mathrm{FO}$ in $\mathrm{BEH}$ strain was an increase in optimal muscle length which did not change in $\mathrm{BEH}+/+$ strain. Severe muscle exercise is associated with muscle damage, increased heterogeneity of sarcomere length and increased muscle optimal length (Proske and Morgan, 2001). Functional overloading does induce muscle damage especially during the first week of its application (Lowe and Alway, 2002). It appears that myostatin dysfunction increases muscle susceptibility to damage after exercise (Mendias et al., 2006, Baltusnikas et al., in press). Indeed, SOL of BEH mice showed a faster drop in peak force in repeated eccentric contractions compared to $\mathrm{BEH}+/+$ strain eventhough muscle CK efflux was similiar. Muscle damage and the associated inflammatory response can inhibit accumulation of contractile proteins and lead to a decrease in specific force (Pizza et al., 2002). Inhibition of signalling by transforming growth factor- $\beta$ (TGF- $\beta$ ) superfamily, which myostatin is a member of, impairs muscle regeneration and leads to a long term deficit in force production after eccentric exercise (McPherron et al., 1997, Gumucio et al., 2013). It appears that myostatin dysfunction interferes with the adaptation of SOL to the overloading. There were no changes in mitochondrial cytochrome c levels, and reduction in force loss during eccentric exercise was not due to improved oxidative capacity of muscles in BEH mice after FO. It is likely that a decrease in specific force might have played an important role in this phenomenon. 
SOL of $\mathrm{BEH}$ and $\mathrm{BEH}+/+$ mice showed similar cytochrome c levels, but twitch contraction time was faster in BEH mice. Myostatin dysfunction leads to an increase in content of faster contracting type IIA, IIX and IIB fibres and reduction in type I fibres in SOL (Amthor et al. 2007, Matsakas et al. 2013). Thus faster twitch contraction time of SOL in $\mathrm{BEH}$ compared to $\mathrm{BEH}+/+$ is in agreement with such a shift in fibre type composition. On the other hand, cytochrome c reflects mitochondrial content which is sensitive to physical activity (Holloszy et al. 1976). Our results suggest that there is no significant difference in mitochondrial content between SOL of $\mathrm{BEH}$ and $\mathrm{BEH}+/+$ mice. There was also no difference in percentage of oxidative fibres in SOL of mice C57BL/6 with and without myostatin $\mathrm{KO}$ (Collins-Hooper et al. 2015). Mouse SOL shows particularly high involvement in postural and locomotor activity compared to other limb muscles (Roy et al. 1991). It is likely that these high levels of physical activity help to maintain high oxidative capacity of SOL in BEH mice with dysfunctional myostatin. Indeed, exercise training of $\mathrm{C} 57 \mathrm{BL} / 6$ mice with myostatin KO induces a marked increase in content of oxidative fibres even in the fast contracting extensor digitorum longus (EDL) with only minor changes in fibre type composition (Matsakas et al. 2013).

\section{Anabolic signalling}

There was no difference between SOL of $\mathrm{BEH}+/+$ and $\mathrm{BEH}$ mice in P70S6K phosphorylation which has been linked to muscle growth in rats (Baar and Esser, 1999). In contrast to the other limb muscles, rat SOL showed only a small increase in P70S6K phosphorylation immediately after electrical stimulation mimicking high resistance exercise and this change became insignificant within 3 hours of recovery. It appears that mouse SOL also shows a reduced signalling through mTOR - P70S6K axis compared to the gastrocnemius muscle which showed increased activation in C57BL/6 mice with myostatin 
knockout (Lipina et al., 2010). Density of activin type IIB receptors (ActRIIB) which mediate myostatin signalling is higher in the faster contracting muscles such as EDL compared to the slower contracting SOL (Medias et al. 2006). Thus myostatin signalling is likely to be weaker in SOL compared to EDL and the gastrocnemius muscle. Indeed, SOL shows smaller hypertrophy compared to both gastrocnemius and EDL in mice with myostatin dysfunction (Amthor et al. 2007). Importance of mTOR signalling for muscle growth varies with time of exposure to the hypertrophic stimuli. P70S6K phosphorylation returns to baseline levels within 21 days of FO in fast twitch plantaris (Hamilton et al., 2014). In general, our results agree with the contention that mTOR signaling is not a predictor of muscle hypertrophy in response to the long term functional overloading.

\section{Perspectives}

Myostatin inhibition has attracted a considerable interest as a strategy for improvement of muscle function. A significant effort has been spent in studying effects of myostatin inhibition on muscle cells and skeletal muscles in various mouse models. Much less attention has been devoted to effects of myostatin dysfunction on the muscle adaptations to various types of functional overloading and muscle exercise. Our results show that BEH mice had experienced a smaller rather than greater gain in SOL mass and, in contrast to $\mathrm{BEH}+/+$ mice, exhibited a decrease in muscle force generating capacity after functional overloading. These results suggest that myostatin dysfunction has a negative effect on adaptation to increased functional demands in skeletal muscles with high levels of motor activity. In our experimental model muscle adaptations to myostatin dysfunction occurred prior to functional overload (FO). Studies employing a model of the conditional myostatin knockout limited to the period of FO are needed to confirm these findings.

\section{Competing interests}


There are no competing interests

\section{Acknowledgments}

This project was also supported by Marie Curie International Reintegration Grant 249156 (A. Lionikas) and the grants VP1-3.1-SMM-01-V-02-003 (A. Kilikevicius) and MIP-067/2012 (T. Venckunas) from the Research Council of Lithuania as well as the grant from the Ministry of Higher Education of Saudi Arabia (Y. Alhind). We wish also to thank Mrs Indre Libnickiene for her excellent technical assistance provided during the project. 


\section{References}

Amthor H, Macharia R, Navarrete R, Schuelke M, Brown SC, Otto A, Voit T, Muntoni F, Vrbova G, Partridge T, Zammit P, Bunger L \& Patel K. Lack of myostatin results in excessive muscle growth but impaired force generation. Proc Natl Acad Sci U S A 2007: 104: $1835-1840$.

Baar K, Esser K. Phosphorylation of p70(S6k) correlates with increased skeletal muscle mass following resistance exercise. Am J Physiol 1999: 276: C120-C127.

Baltusnikas J, Kilikevicius A, Venckunas T, Fokin A, Lionikas A, Ratkevicius A. Regenerated soleus muscle shows reduced creatine kinase efflux after contractile activity in vitro. Appl Physiol Nutr Metab 2015: 40: 129-133.

Baltusnikas J, Kilikevicius A, Venckunas T, Fokin A, Bünger L, Lionikas A, Ratkevicius A. Myostatin dysfunction impairs force generation in extensor digitorum longus muscle and increases exercise-induced protein efflux from extensor digitorum longus and soleus muscles. Appl Physiol Nutr Metab (In press).

Bloemberg D, Quadrilatero J. Rapid determination of myosin heavy chain expression in rat, mouse, and human skeletal muscle using multicolor immunofluorescence analysis. PLoS One 2012: 7: e35273, DOI: 10.1371/journal.pone.0035273.

Bodine SC, Baar K (2012). Analysis of skeletal muscle hypertrophy in models of increased loading. Methods Mol Biol 2012: 798: 213-229.

Bogdanovich S, Krag TO, Barton ER, Morris LD, Whittemore LA, Ahima RS, Khurana TS. Functional improvement of dystrophic muscle by myostatin blockade. Nature 2002: 420: 418-421.

Bottinelli R, Canepari M, Pellegrino MA, Reggiani C. Force-velocity properties of human skeletal muscle fibres: myosin heavy chain isoform and temperature dependence. $\mathrm{J}$ Physiol 1996: 495 (Pt 2), 573-586. 
Brooks SV \& Faulkner JA. Contractile properties of skeletal muscles from young, adult and aged mice. J Physiol 1988: 404, 71-82.

Bunger L, Ott G, Varga L, Schlote W, Rehfeldt C, Renne U, Williams JL \& Hill WG. Marker-assisted introgression of the Compact mutant myostatin allele MstnCmpt-dl1 Abc into a mouse line with extreme growth effects on body composition and muscularity. Genet Res 2004: 84, 161-173.

Collins-Hooper H, Sartori R, Giallourou N, Matsakas A, Mitchell R, Mararenkova H, Flasskamp H, Macharia R, Ray S, Swann JR, Sandri M, Patel K. Symmorphosis through Dietary Regulation: A Combinatorial Role for Proteolysis, Autophagy and Protein Synthesis in Normalising Muscle Metabolism and Function of Hypertrophic Mice after Acute Starvation. PLoS One 2015: 10: e0120524, DOI: 10.1371/journal.pone.0120524.

Darveau C-A, Suarez RK, Andrews RD, Hochachka PW. Allometric cascade as a unifying principle of body mass effects on metabolism. Nature 2002: 417, 166-170.

Goodman CA, Frey JW, Mabrey DM, Jacobs BL, Lincoln HC, You JS, Hornberger TA. The role of skeletal muscle mTOR in the regulation of mechanical load-induced growth. $\mathrm{J}$ Physiol 2011: 589: 5485-5501.

Goodman CA, McNally RM, Hoffmann FM, Hornberger TA. Smad3 Induces Atrogin-1, Inhibits mTOR and Protein Synthesis, and Promotes Muscle Atrophy In Vivo. Mol Endocrinol 2013: 27: 1946-1957.

Gumucio JP, Flood MD, Phan AC, Brooks SV, Mendias CL. Targeted inhibition of TGF- $\beta$ results in an initial improvement but long-term deficit in force production after contraction-induced skeletal muscle injury. J Appl Physiol 2013: 115: 539-545.

Hamilton DL, Philp A, MacKenzie MG, Baar K. A limited role for PI $(3,4,5) \mathrm{P} 3$ regulation in controlling skeletal muscle mass in response to resistance exercise. PLoS One 2010: 5: e11624, DOI: 10.1371/journal.pone.0011624; 10.1371/journal.pone.0011624. 
Hamilton DL, Philp A, MacKenzie MG, Patton A, Towler MC, Gallagher IJ, Bodine SC, Baar K. Molecular brakes regulating mTORC1 activation in skeletal muscle following synergist ablation. Am J Physiol Endocrinol Metab 2014: 307: E365-E373.

Holloszy JO, Booth FW. Biochemical adaptations to endurance exercise in muscle. Annu Rev Physiol 1976: 38: 273-291.

Kandarian SC, White TP. Force deficit during the onset of muscle hypertrophy. J Appl Physiol 1989: 67: 2600-2607.

Kilikevicius A, Venckunas T, Zelniene R, Carroll AM, Lionikaite S, Ratkevicius A, Lionikas A. Divergent physiological characteristics and responses to endurance training among inbred mouse strains. Scand J Med Sci Sports 2012: 23(5): 657-668.

Lionikas A, Kilikevicius A, Bunger L, Meharg C, Carroll AM, Ratkevicius A, Venckunas T, Blizard DA. Genetic and genomic analyses of musculoskeletal differences between BEH and BEL strains. Physiol Genomics 2013: 45: 940-947.

Lipina C, Kendall H, McPherron AC, Taylor PM, Hundal HS. Mechanisms involved in the enhancement of mammalian target of rapamycin signalling and hypertrophy in skeletal muscle of myostatin-deficient mice. FEBS Lett 2010: 584: 2403-2408.

Lowe DA, Alway SE. Animal models for inducing muscle hypertrophy: are they relevant for clinical applications in humans?. J Orthop Sports Phys Ther 2002: 32, 36-43.

MacKenzie MG, Hamilton DL, Pepin M, Patton A, Baar K. Inhibition of myostatin signaling through Notch activation following acute resistance exercise. PLoS One 2013: 8: e68743, DOI: 10.1371/journal.pone.0068743.

Matsakas A, Macharia R, Otto A, Elashry MI, Mouisel E, Romanello V, Sartori R, Amthor H, Sandri M, Narkar V, Patel K. Exercise training attenuates the hypermuscular phenotype and restores skeletal muscle function in the myostatin null mouse. Exp Physiol 2012: 97: 125-140. 
Matsakas A, Mouisel E, Amthor H, Patel K. Myostatin knockout mice increase oxidative muscle phenotype as an adaptive response to exercise. J Muscle Res Cell Motil 2010: 31: 111-125.

Matsakas A, Romanello V, Sartori R, Masiero E, Macharia R, Otto A, Elashry M, Sandri M, Patel K. Food restriction reverses the hyper-muscular phenotype and force generation capacity deficit of the myostatin null mouse. Int J Sports Med 2013: 34: 223-231.

McPherron AC, Lawler AM, Lee SJ. Regulation of skeletal muscle mass in mice by a new TGF-beta superfamily member. Nature 1997: 387: 83-90.

Mendias CL, Marcin JE, Calerdon DR, Faulkner JA. Contractile properties of EDL and soleus muscles of myostatin-deficient mice. J Appl Physiol 2006: 101, 898-905.

Pizza FX, Koh TJ, McGregor SJ, Brooks SV. Muscle inflammatory cells after passive stretches, isometric contractions, and lengthening contractions. J Appl Physiol 2002: 92, 1873-1878.

Proske U, Morgan DL. Muscle damage from eccentric exercise: mechanism, mechanical signs, adaptation and clinical applications. J Physiol 2001: 537: 333-345.

Qaisar R, Renaud G, Morine K, Barton ER, Sweeney HL, Larsson L. Is functional hypertrophy and specific force coupled with the addition of myonuclei at the single muscle fiber level? FASEB J 2012: 26: 1077-1085.

Ratkevicius A, Carroll AM, Kilikevicius A, Venckunas T, McDermott KT, Gray SR, Wackerhage $\mathrm{H}$, Lionikas A. H55N polymorphism as a likely cause of variation in citrate synthase activity of mouse skeletal muscle. Physiol Genomics 2010: 42A: 96-102.

Ratkevicius A, Joyson A, Selmer I, Dhanani T, Grierson C, Tommasi AM, DeVries A, Rauchhaus P, Crowther D, Alesci S, Yaworsky P, Gilbert F, Redpath TW, Brady J, Fearon KC, Reid DM, Greig CA, Wackerhage H. Serum concentrations of myostatin and 
myostatin-interacting proteins do not differ between young and sarcopenic elderly men. $\mathrm{J}$ Gerontol A Biol Sci Med Sci 2011: 66: 620-626.

Roy RR, Hutchison DL, Pierotti DJ, Hodgson JA, Edgerton VR. EMG patterns of rat ankle extensors and flexors during treadmill locomotion and swimming. J Appl Physiol 1991: $70,2522-2529$.

Smerdu V, Erzen I. Dynamic nature of fibre-type specific expression of myosin heavy chain transcripts in 14 different human skeletal muscles. J Muscle Res Cell Motil 2001: 22, 647-655.

Smith RC \& Lin BK (2013). Myostatin inhibitors as therapies for muscle wasting associated with cancer and other disorders. Curr Opin Support Palliat Care 2013: 7: 352-360.

Stewart VH, Saunders DH, Greig CA. Responsiveness of muscle size and strength to physical training in very elderly people: A systematic review. Scand J Med Sci Sports 2013: DOI: $10.1111 /$ sms.12123.

Verdijk LB, Gleeson BG, Jonkers RA, Meijer K, Savelberg HH, Dendale P, van Loon LJ. Skeletal muscle hypertrophy following resistance training is accompanied by a fiber typespecific increase in satellite cell content in elderly men. J Gerontol A Biol Sci Med Sci 2009: 64: 332-339.

Watt KI, Jaspers RT, Atherton P, Smith K, Rennie MJ, Ratkevicius A, Wackerhage H. SB431542 treatment promotes the hypertrophy of skeletal muscle fibers but decreases specific force. Muscle Nerve 2010: 41: 624-629. 
1

2

3

4

5

6

7

8

9

10

11

12

13

14

15

16

17

18

19

20

21

22

23

24

25

26

27

28

29

30

31

32

33

34

35

36

37

38

39

40

41

42

43

44

45

46

47

48

49

50

51

52

53

54

55

56

57

58

59

60

Table 1. Body mass of experimental $\mathrm{BEH}+/+(\mathrm{n}=12)$ and $\mathrm{BEH}(\mathrm{n}=9)$ mice that were subjected to functional overloading (FO) of soleus (SOL) muscle and body mass of aged matched $\mathrm{BEH}+/+(\mathrm{n}=12)$ and $\mathrm{BEH}(\mathrm{n}=12)$ mice that were not subjected to any interventions.

\begin{tabular}{lccc}
\hline & \multicolumn{2}{c}{ Experimental mice } & Control mice \\
\cline { 2 - 4 } & Before FO & After FO \\
& 14 weeks & 18 weeks & 18 weeks \\
\hline BEH $+/+(\mathrm{g})$ & $54.0 \pm 3.3$ & $54.1 \pm 3.3$ & $52.0 \pm 3.6$ \\
& & & $60.2 \pm 3.1^{* * *}$ \\
\hline BEH $(\mathrm{g})$ & $61.0 \pm 4.0^{* * *}$ & $60.4 \pm 4.4^{* * *}$ & \\
\hline & & & \\
\hline
\end{tabular}



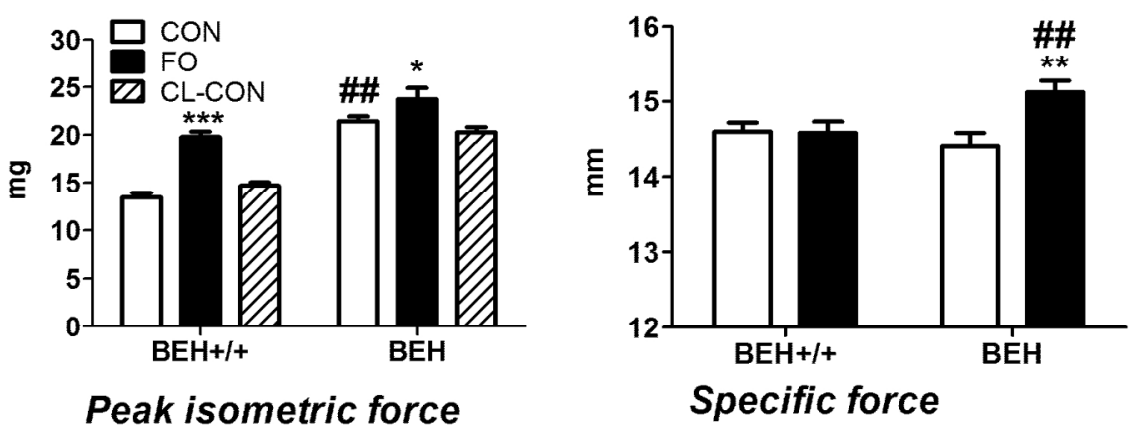

Peak isometric force
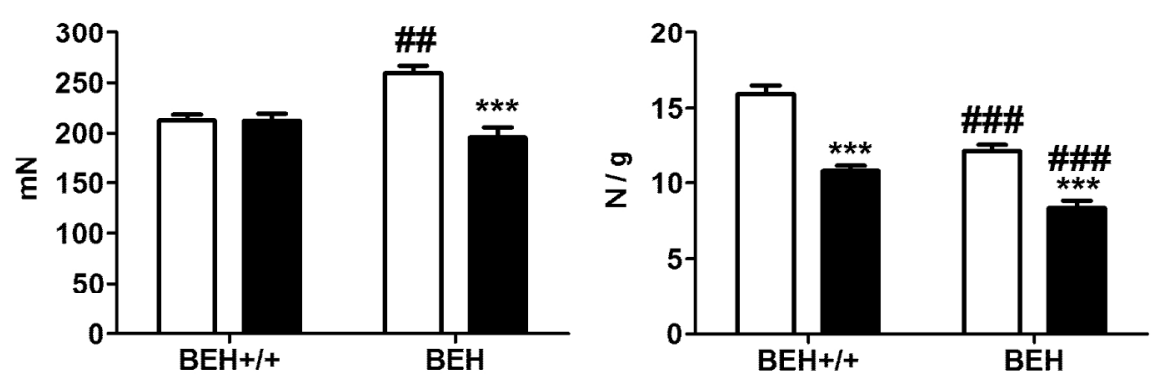

Fig. 1. Muscle mass, optimal length, peak isometric force and specific force of soleus muscles (SOL) in the control mice (CON) and after 28 days of functional overloading (FO) with the respective contralateral controls $(\mathrm{CL}-\mathrm{CON})$ where appropriate for $\mathrm{BEH}+/+(\mathrm{n}=12)$ and $\mathrm{BEH}(\mathrm{n}=9)$ mice. Values are means $\pm \mathrm{SEM}$; * $\mathrm{P}<0.05, * * * \mathrm{P}<0.001$ between CON and $\mathrm{FO} ; \# \# \mathrm{P}<0.01$, \#\#\# $\mathrm{P}<0.001$ between $\mathrm{BEH}+/+$ and $\mathrm{BEH}$ muscles.

$169 \times 121 \mathrm{~mm}(300 \times 300 \mathrm{DPI})$ 
Fig 2. Twitch contractile properties of soleus muscle (SOL) in the control (CON) BEH+/+ $(n=12)$ and $B E H$ $(n=12)$ mice and after 28 days of functional overloading (FO) for $B E H+/+(n=12)$ and $B E H(n=9)$ mice. Values are means \pm SEM; \#\#\# $\mathrm{P}<0.001$ between the respective $\mathrm{BEH}+/+$ and $\mathrm{BEH}$ mice. $145 \times 257 \mathrm{~mm}(300 \times 300$ DPI $)$ 


\section{p70S6K phosporylation}
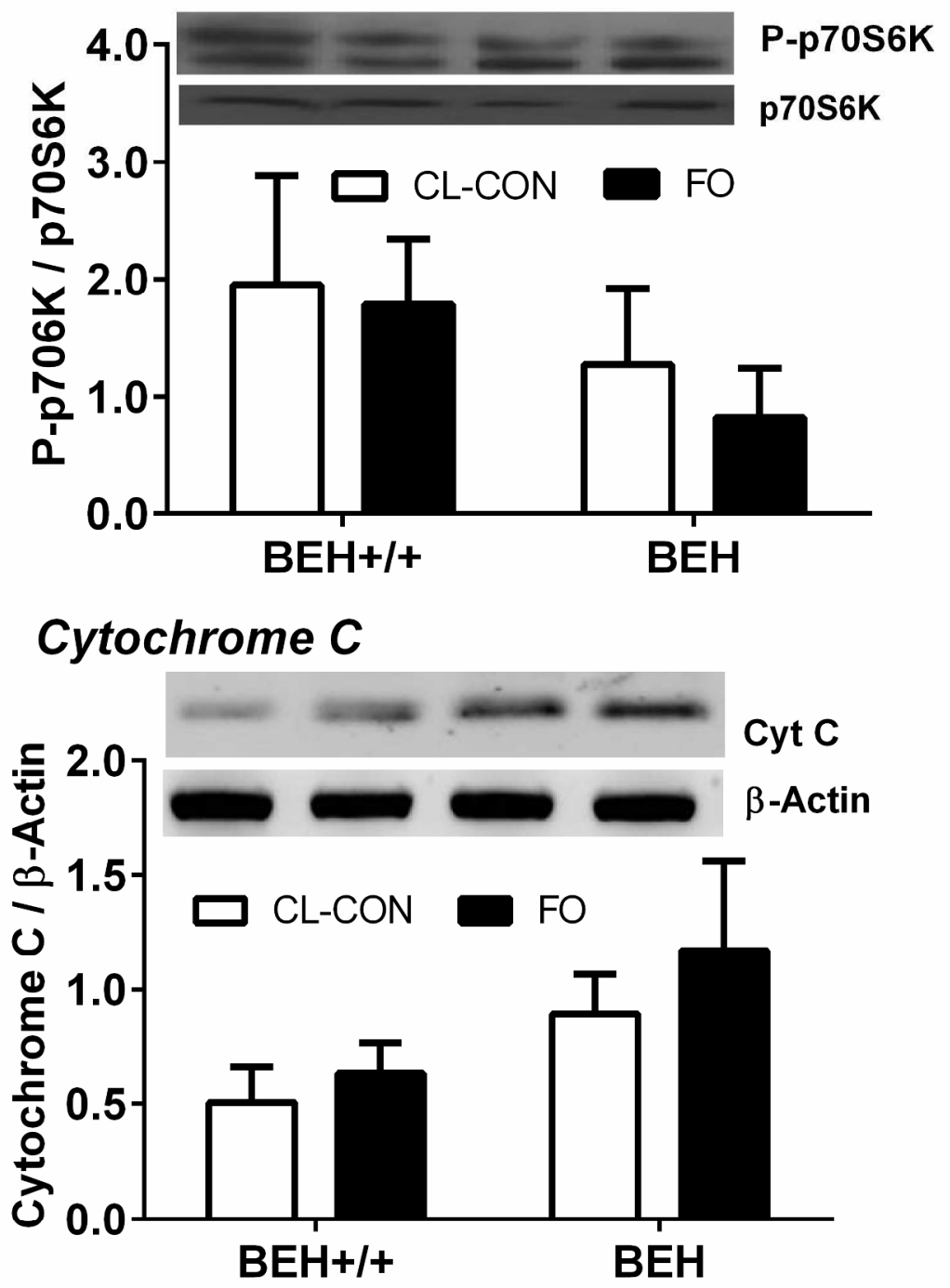

Fig. 3. p70S6K phosphorylation (P-p70S6K / p70S6K ratio) and cytochorome c (Cyt C) in the soleus muscle (SOL). Western blotting was performed on the muscles after 28 days of functional overloading (FO) for $\mathrm{BEH}+/+(n=6)$ and $\mathrm{BEH}(n=6)$ mice and the respective contralateral controls $(\mathrm{CL}-\mathrm{CON})$. The representative Western blots are shown for each of the four studied muscle groups in the same order as bars in the figure.

Values are means \pm SEM. $207 \times 277 \mathrm{~mm}(300 \times 300 \mathrm{DPI})$ 
Fig 4. Peak isometric force in eccentric exercise and the exercise induced creatine kinase efflux for soleus muscle $(\mathrm{SOL})$ in the control $(\mathrm{CON}) \mathrm{BEH}+/+(n=12)$ and $\mathrm{BEH}(\mathrm{n}=12)$ mice as well as after 28 days of functional overloading (FO) for $\mathrm{BEH}+/+(\mathrm{n}=12)$ and $\mathrm{BE}(\mathrm{n}=9)$ mice, respectively. Values are means \pm S.E.M. As indicated for the control condition, the difference between $\mathrm{BEH}+/+$ and $\mathrm{BEH}$ ranged from $\mathrm{P}<0.05$ after 5 contractions to $\mathrm{P}<0.0001$ after 20 contractions. $193 \times 257 \mathrm{~mm}(300 \times 300 \mathrm{DPI})$ 